\title{
Environmentally triggered genomic plasticity and capsular polysaccharide formation are involved in increased ethanol and acetic acid tolerance in Kozakia baliensis NBRC 16680
}

\author{
Julia U. Brandt, Friederike-Leonie Born, Frank Jakob*i[ and Rudi F. Vogel
}

\begin{abstract}
Background: Kozakia baliensis NBRC 16680 secretes a gum-cluster derived heteropolysaccharide and forms a surface pellicle composed of polysaccharides during static cultivation. Furthermore, this strain exhibits two colony types on agar plates; smooth wild-type (S) and rough mutant colonies (R). This switch is caused by a spontaneous transposon insertion into the gumD gene of the gum-cluster, resulting in a heteropolysaccharide secretion deficient, rough phenotype. To elucidate, whether this is a directed switch triggered by environmental factors, we checked the number of $\mathrm{R}$ and $\mathrm{S}$ colonies under different growth conditions including ethanol and acetic acid supplementation. Furthermore, we investigated the tolerance of $\mathrm{R}$ and $\mathrm{S}$ strains against ethanol and acetic acid in shaking and static growth experiments. To get new insights into the composition and function of the pellicle polysaccharide, the polE gene of the R strain was additionally deleted, as it was reported to be involved in pellicle formation in other acetic acid bacteria.

Results: The number of $R$ colonies was significantly increased upon growth on acetic acid and especially ethanol. The morphological change from K. baliensis NBRC $16680 \mathrm{~S}$ to R strain was accompanied by changes in the sugar contents of the produced pellicle EPS. The R:ApolE mutant strain was not able to form a regular pellicle anymore, but secreted an EPS into the medium, which exhibited a similar sugar monomer composition as the pellicle polysaccharide isolated from the $\mathrm{R}$ strain. The R strain had a markedly increased tolerance towards acetic acid and ethanol compared to the other NBRC 16680 strains (S, R:ApolE). A relatively high intrinsic acetic acid tolerance was also observable for K. baliensis DSM 14400', which might indicate diverse adaptation mechanisms of different $K$. baliensis strains in altering natural habitats.

Conclusion: The results suggest that the genetically triggered $\mathrm{R}$ phenotype formation is directly related to increased acetic acid and ethanol tolerance. The polE gene turned out to be involved in the formation of a cell-associated, capsular polysaccharide, which seems to be essential for increased ethanol/acetic tolerance in contrast to the secreted gum-cluster derived heteropolysaccharide. The genetic and morphological switch could represent an adaptive evolutionary step during the development of $K$. baliensis NBRC 16680 in course of changing environmental conditions.
\end{abstract}

Keywords: Kozakia baliensis, Heteropolysaccharides, Pellicle, Ethanol/acetic acid tolerance, Adaptive evolution

\footnotetext{
* Correspondence: frank.jakob@wzw.um.de

Technische Universität München, Lehrstuhl für Technische Mikrobiologie,

Gregor-Mendel-Straße 4, 85354 Freising, Germany
} 


\section{Background}

Gram-negative bacteria produce extracellular hetero(HePS) or homopolysaccharides (HoPS), which are attached to the bacterial cell as capsular polysaccharide (CPS) or secreted into the environment as extracellular polysaccharide (EPS). Bacterial polysaccharides are important for the survival of bacteria, for instance in bacteria-host interaction, biofilm formation [1] and stress adaptation [2].

Acetic acid bacteria (AAB) are obligate aerobes and belong to the class of $\alpha$-Proteobacteria. They are oxidative bacteria that strongly oxidize ethanol to acetic acid. AAB are well known for their ability to produce large amounts of EPSs, either HoPS, like dextrans, levans [3-5] and cellulose, or different kinds of HePS, such as acetan [6] and gluconacetan [7]. Furthermore, a variety of AAB has the ability to grow floating on the surface of a static culture by producing a pellicle enabling a high aeration state. The pellicle consists of an accumulation of cells, which are tightly associated with each other by capsular polysaccharides as connecting element. The pellicle CPS can be a HoPS of cellulose, which is produced by many Komagataeibacter species, like Komagataeibacter (K.) xylinus [8] (formerly Gluconobacter (G.) xylinum [9]), or a HePS, such as produced by many Acetobacter strains [10-12]. This HePS can be composed of different sugar monomers, like the HePS of $A$. tropicalis SKU1100. which consists of glucose, galactose, and rhamnose [13] or of $A$. aceti IFO3284 that contains only glucose and rhamnose [10].

The genes involved in the cellulose pellicle biosynthesis are arranged in an operon structure, like the acs operon [13] or the bcs operon [14], and widely studied. It is assumed that the genes involved in the synthesis of other pellicle HePS in AAB are assigned to a particular cluster, called pol-cluster. Deeraksa et al. (2005) could show, that the pellicle HePS produced by $A$. tropicalis SKU1100 could be traced back to a gene cluster, polABCDE, which is required for pellicle formation. In this operon, the polABCD genes showed high similarity to $r f b B A C D$ genes, which are involved in dTDP-l-rhamnose biosynthesis. The downstream located polE gene showed only low similarity to known glycosyltransferases, whereas a transposoninduced disruption of the polE gene resulted in a non pellicle forming strain, due to the absence of CPS production. Instead of the CPS, however, the $\mathrm{Pel}^{-}$strain showed a smooth-surfaced colony and the HePS was now secreted into the medium, which had the same composition as the capsular pellicle polysaccharide [11].

Acetobacter species are further known to exhibit high natural mutation frequencies $[15,16]$, also resulting in the formation of two or more different colony types. A. pasteurianus IFO3284 produces two altering types of colonies on agar medium that are inter-convertible by spontaneous mutation; a rough surface colony that can produce a pellicle ( $\mathrm{R}$ strain) and smooth surface colony, which cannot produce a pellicle (S strain) [17]. Furthermore the R strains tolerate higher concentrations of acetic acid, whereas the pellicle formation is directly related to acetic acid resistance $[18,19]$. It is further assumed that the pellicle CPS functions as a barrier-like biofilm against passive diffusion of acetic acid into the cells [18].

Microorganisms constantly face many difficult challenges, due to changing environmental conditions. The capacity to maintain functional homeostasis is essential for their survival. Recently, we have shown that the AAB Kozakia (K.) baliensis NBRC 16680 forms large amounts of a soluble unique HePS in the medium, as well as a pellicle during static cultivation [20]. Furthermore, $K$. baliensis NBRC 16680 forms a second type of colony form: a non-HePS producing rough-surfaced colony ( $\mathrm{R}$ strain), caused by a transposon insertion into the gumD gene of the corresponding gum-like HePS cluster. The reason for this transposon insertion is unclear, whereby it was assumed that the transposon insertion represents a directed event, triggered by external factors.

Therefore, we investigated in this study, whether the morphology switch of $K$. baliensis NBRC 16680 is a random event, or triggered by environmental adaptations. In order to check if the morphological switch is connected to the formation of a CPS used in pellicle formation, we performed a $\triangle p o l E$ deletion in K. baliensis NBRC $16680 \mathrm{R}$ via a two step marker less gene deletion system. The different mutants were investigated regarding their growth and EPS production under different growth conditions including ethanol and acetic acid stress.

\section{Methods}

Bacterial strains, culture media, and culture conditions. K. baliensis (NBRC 16680; National Institute of Technology and Evaluation (NITE) Biological Resource Center, Japan, DSM 14400; German Collection of Microorganisms and Cell Cultures(DSMZ)), as well as a mutant strain of $K$. baliensis NBRC $16680 \mathrm{R}(\Delta g u m D)$ [20], with a rough phenotype, were used in this study. K. baliensis and its derivatives were grown at $30{ }^{\circ} \mathrm{C}$ in $\mathrm{NaG}$ media consisting of $20 \mathrm{~g} / \mathrm{L}$ sodium gluconate, $3 \mathrm{~g} / \mathrm{L}$ yeast extract, $2 \mathrm{~g} / \mathrm{L}$ peptone, $3 \mathrm{~g} / \mathrm{L}$ glycerol, $10 \mathrm{~g} / \mathrm{L}$ mannitol and a $\mathrm{pH}$ adjusted to 6.0. E. coli strain TOP10 (Invitrogen, Karlsruhe, Germany), was grown at $37{ }^{\circ} \mathrm{C}$ and $180 \mathrm{rpm}$ on a rotary shaker in LB medium consisting of $5 \mathrm{~g}$ yeast extract, $5 \mathrm{~g} \mathrm{NaCl}$ and $10 \mathrm{~g}$ peptone. For selection of plasmids in E. coli TOP10. $50 \mu \mathrm{g} /$ $\mathrm{mL}$ kanamycin was added to the LB medium. For selection of recombinant $K$. baliensis strains $50 \mu \mathrm{g} / \mathrm{mL}$ kanamycin or $60 \mu \mathrm{g} / \mathrm{mL}$ Fluorocytosin (FC) were used.

\section{Convertibility of $K$. baliensis NBRC 16680 from wild-type (S) to rough strains (R)}

The number of $\mathrm{R}$ strains was determined during/after cultivation of $K$. baliensis NBRC 16680 in standard NaG 
medium, NaG medium supplemented with 3\% ethanol (NaG-EtOH) or $0.4 \%$ acetic acid (NaG-AA), respectively. $K$. baliensis NBRC 16680 was first cultivated overnight in $10 \mathrm{ml}$ of unmodified $\mathrm{NaG}$ medium at $30{ }^{\circ} \mathrm{C}(200 \mathrm{rpm})$. About $1 \times 10^{8} \mathrm{CFU} / \mathrm{mL}$ seed culture was afterwards transferred to $10 \mathrm{ml}$ of standard or modified NaG medium, respectively. The flasks were incubated at $30{ }^{\circ} \mathrm{C}$ with rotary shaking at $200 \mathrm{rpm}$ for $48 \mathrm{~h}$ and samples adducted at 0,24 and $48 \mathrm{~h}$. Cell numbers of wild-type and rough colonies $(\triangle g u m D)$ were counted on non-modified NaG agar plates. Each growth experiment in liquid culture was performed thrice in separate assays, while each assay contained further three technical plating replicates.

For targeting the transposon insertion side, random colony PCRs of 23 rough colonies were carried out with Phire Hot start DNA polymerase (Thermo Fisher scientific; Waltham, USA). A primer set of a genomic primer (G4F_Fw) and a primer, targeting the mobile element (TE_Rv) were used; primers are listed in Additional file 1. PCR products were subsequently sequenced via Sanger sequencing by GATC Biotech (Konstanz, Germany).

\section{Deletion of the polE gene with a two step marker less gene deletion system}

For plasmids preparation, the GeneJET Plasmid Miniprep Kit (Thermo Fisher scientific, Waltham, USA) was used. Genomic DNA from $K$. baliensis NBRC $16680 \mathrm{R}$ was extracted with the E.Z.N.A. Bacterial DNA Kit (Omega Biotek, Norcross, USA) and DNA purification was done with the E.Z.N.A. Cycle-Pure Kit (Omega Bio-tek, Norcross, USA). Restriction enzymes, DNA ligase, and alkaline phosphatase (FastAP) were obtained from Fermentas (Waltham, USA). PCRs were performed according to the Phusion High-Fidelity DNA Polymerase manuals from New England Biolabs (Frankfurt, Germany). For construction of the deletion vector, a fusion PCR technique was used to ligate the PCR products of flanking regions according to a long flanking homology (LFH) protocol [21, 22]. The length of the homology sequences were $20 \mathrm{bp}$. Primers are listed in Additional file 1. An enzyme-free cloning technique [23] was used for the further construction of the deletion vector, with the pKOS6b plasmid as basis, including a multiple cloning site (MCS), a kanamycine resistance gene $\left(\mathrm{KM}^{\mathrm{R}}\right)$ and the $\operatorname{cod} A$ and $\operatorname{cod} B$ gene (Additional file 2A) [24]. Flanking regions of the polE gene, covering approximately $950 \mathrm{bp}$ of the upstream and downstream region of the polE gene were amplified via PCR. The upstream region of $957 \mathrm{bp}$ was amplified with primer P1_polE_KpnI_Fw and P2-polE_Rv, and a second primer set amplified the downstream region (968 bp) of the polE gene, containing the primers P3_polE_Fw and P4-polE_XbaI_Rv (Additional file 1 \& Additional file 2A). In the following step, a LFH PCR [21] was performed with P1_polE_KpnI_Fw and P4-polE_XbaI_Rv to merge the two previously amplified fragments (1898 bp). The fused fragment, as well as the pKOS6b vector, were both digested (KpnI, XbaI) and finally ligated. The resulting deletion vector, $\mathrm{pKOS6 \textrm {b }} \triangle \mathrm{polE}$, was verified via sanger sequencing (pK18MCS_Fw \& pK18MCS_Rv), and further amplified in E. coli TOP 10. The transformation of $\mathrm{pKOS} 6 \mathrm{~b} \triangle$ polE into K. baliensis NBRC $16680 \mathrm{R}$, was carried out by electroporation [25-28] with Gene Pulser Xcell ${ }^{\text {Tn }}$ Electroporation Systems from Bio Rad (München, Germany). Therefore, cells were inoculated to an $\mathrm{OD}_{600}$ of 0.3 in NaG medium and finally grown to an $\mathrm{OD}_{600}$ of 0.9 . The culture was centrifuged at $5000 \mathrm{~g}$, at $4{ }^{\circ} \mathrm{C}$ for $10 \mathrm{~min}$, and washed three times in $1 \mathrm{mM}$ HEPES buffer (pH 7). Cells were resuspended in $1 \mathrm{mM}$ HEPES buffer, supplemented with $1 / 4$ volume of glycerin and shock frozen in $50 \mu \mathrm{L}$ aliquots. The electroporation took place in cuvettes with $2 \mathrm{~mm}$ electrode distance from Bio Rad (München, Germany). The electroporation was carried out under constant conditions: $2.5 \mathrm{kV}, 25 \mu \mathrm{F}$, and $400 \Omega$. Fresh enriched $\mathrm{NaG}$ medium (450 mM mannitol, $15 \mathrm{~g} / \mathrm{L}$ yeast extract, $15 \mathrm{mM} \mathrm{CaCl}_{2}$, $10 \mathrm{mM} \mathrm{MgSO}_{4}$ and $6 \mathrm{mM}$ glycerin) was added immediately after the pulse. The treated cells were incubated on a rotary shaker over $14 \mathrm{~h}$ and subsequently plated on $\mathrm{NaG}$ plates containing $50 \mu \mathrm{g} / \mathrm{mL}$ kanamycin for the first selection step with an incubation time of $48 \mathrm{~h}$. During the first recombination step on NaG-Kan plates, a random chromosomal integration of the plasmid took place, which was checked by colony PCR using a specific primer set of a plasmid (pK18MCS_Fw or pK18MCS_Rv) and a genome (CL_polE_Fw or $\mathrm{CL} \_$polE_Rv) specific primer. Phire Hot start DNA polymerase (Thermo Fisher scientific; Waltham, USA) was used for colony PCR reactions, to screen for mutants or to confirm integration of the deletion vector into the genome. PCR products were sequenced via sanger sequencing by GATC Biotech (Konstanz, Germany). The positive clones were further grown on $\mathrm{NaG}$-plates with $60 \mu \mathrm{g} / \mathrm{ml} \mathrm{FC}$, to drive the directed loss of the plasmid and the final selection of $K$. baliensis NBRC $16680 \mathrm{R} \Delta$ polE mutant colonies. After 3 days of incubation, the correct $\triangle p o l E$ mutant colonies could be identified via colony PCR, with a genome specific primer set $\left(\mathrm{CL}_{\_} \_\right.$polE_Fw \& $\mathrm{CL} \_$po$l E \_$Rv) resulting in a $1950 \mathrm{bp}$ fragment for the $\triangle p o l E \mathrm{mu}$ tant and a 3000 bp fragment for K. baliensis NBRC 16680 $\mathrm{R}$ (Additional file $2 \mathrm{C}$ ).

\section{Growth behavior of different $K$. baliensis strains in acetic acid and ethanol}

K. baliensis DSM 14400. NBRC 16680. the $\triangle g u m D$ mutant [20] and the $\triangle p o l E$ mutant strain (see 2.3) were grown on $\mathrm{NaG}$ agar plates, directly plated from the particular cryo stock, with either ethanol or acetic acid, in different concentrations. The ethanol supplemented plates contained 1\% - $10 \%$ of ethanol $(\mathrm{v} / \mathrm{v}$, at intervals of $1 \%)$ and the acetic acid supplemented plates $0.1 \%-1 \%$ of acetic acid $(v / v$, at 
intervals of $0.1 \%)$. Each strain was streaked onto the plates from cryo-stocks and incubated for 3 days at $30^{\circ} \mathrm{C}$.

Furthermore, a static cultivation in $\mathrm{NaG}$ medium with $3 \%$ ethanol and $0.6 \%$ acetic acid was carried out. The $K$. baliensis NBRC 16680 strain, $\mathrm{R}$ mutant [20] and the $\Delta p o l E$ mutant (see below) were grown as seed cultures in unmodified NaG media, overnight. Cultures were inoculated with an $\mathrm{OD}_{600} 0.3$ and cultivated up to 0.9 , respectively. For static cultures, $300 \mu \mathrm{l}$ of the seed culture were inoculated into $3 \mathrm{ml} \mathrm{NaG}$ medium and cultivated statically at $30{ }^{\circ} \mathrm{C}$. Cells were harvested by centrifugation at $6000 \mathrm{~g}$ and cell pellets were dried overnight at $120{ }^{\circ} \mathrm{C}$. The dry weight was measured each day, over a time span of 7 days.

\section{Analysis of HePS composition}

Main cultures of $K$. baliensis NBRC 16680. $\triangle g u m D$ mutant [20] and $\triangle p o l E$ mutant (see below) were performed in $500 \mathrm{~mL}$ Erlenmeyer flasks with $50 \mathrm{~mL}$ of modified $\mathrm{NaG}$ media, inoculated with $500 \mu \mathrm{l}$ of the pre-cultures and kept at $30{ }^{\circ} \mathrm{C}$ in a rotary shaker $(200 \mathrm{rpm})$ for $32 \mathrm{~h}$. Afterwards, cells were removed and the EPS containing supernatants were precipitated with cold ethanol $(2: 1, v / \mathrm{v})$ and kept overnight at $4{ }^{\circ} \mathrm{C}$. This step was repeated three times, followed by a dialysis step (MWCO $14 \mathrm{kDa}$ ) of the recovered (centrifugation) and in $\mathrm{ddH}_{2} \mathrm{O}$ re-dissolved HePS. Finally, the purified HePSs were lyophilized and quantified by weighing. To obtain large amounts of pellicle EPS, $K$. baliensis NBRC $16680 \mathrm{R}$ [20] and the $\triangle$ polE mutant (see 2.3) were cultured in unmodified $\mathrm{NaG}$ medium in cell culture flasks (Greiner Bio-One, Austria), to ensure a large surface for oxygen supply. Briefly, $10 \%$ of the seed culture was inoculated to $30 \mathrm{~mL} \mathrm{NaG}$ medium and incubated statically at $30{ }^{\circ} \mathrm{C}$ for 14 days. The pellicle EPS was purified from the culture and cells were separated from EPS via ultra-sonification (10 $\mathrm{min}$ ) and mechanical disruption, related to the method of IAI Ali, Y Akakabe, S Moonmangmee, A Deeraksa, M Matsutani, $\mathrm{T}$ Yakushi, $\mathrm{M}$ Yamada and K Matsushita [11]. The culture was centrifuged (10 min, $10.000 \mathrm{~g}$ ) and the supernatant was saved in another flask. The cell pellet was washed 2 times with $10 \mathrm{mM}$ HEPES buffer (pH 7), and suspended in the same buffer. The suspension was again ultra-sonicated for $10 \mathrm{~min}$, followed by a centrifugation step for $10 \mathrm{~min}$, $13.000 \mathrm{~g}$. The resulting supernatant was combined, with the present supernatant from the first centrifugation, and EPS was precipitated with cold ethanol $(2: 1, v / \mathrm{v})$ and kept overnight at $4{ }^{\circ} \mathrm{C}$. This step was repeated three times, followed by a dialysis step (MWCO $14 \mathrm{kDa}$ ) of the recovered (centrifugation) and in $\mathrm{ddH}_{2} \mathrm{O}$ re-dissolved EPS.

The monosaccharide composition of the isolated $K$. baliensis NBRC $16680 \mathrm{R}$ pellicle or secreted HePS (NBRC 16680. $\triangle p o l E$ ) was investigated via high performance liquid chromatography (HPLC). For HPLC analysis the purified polysaccharide samples were hydrolyzed with $10 \%$ of perchloric acid over $7 \mathrm{~h}$ at $100{ }^{\circ} \mathrm{C}$, followed by a centrifugation step $\left(4{ }^{\circ} \mathrm{C}, 10 \mathrm{~min}, 13,000 \mathrm{~g}\right)$ for removal of possible impurities, such as proteins. For the HPAEC analysis polysaccharide samples were hydrolyzed with $10 \%$ of perchloric acid over $2 \mathrm{~h}$ at $100{ }^{\circ} \mathrm{C}$, as well followed by a centrifugation step $\left(4{ }^{\circ} \mathrm{C}, 10 \mathrm{~min}\right.$, $13,000 \mathrm{~g})$. The samples were further dissolved (1:10 or 1:100). The supernatant was analyzed using a Rezex RPM column (Phenomenex, Germany) coupled to a refractive index (RI) detector (Gynkotek, Germany) corresponding to the method of [29]. Sugar monomers were identified according to their retention time using suitable monosaccharide standards (D-glucose, D-galactose, D-mannose, D-rhamnose). The mobile phase was water, with a flow rate of $0.6 \mathrm{~mL} / \mathrm{min}$.

\section{Results}

Mutation of $K$. baliensis NBRC 16680 from S to R phenotype in dependence of different growth conditions

In K. baliensis NBRC 16680 spontaneous mutations occur, which cause a non-slimy phenotype, referred as rough (R) strain. In a previous work we have demonstrated, that this mutation can result from a transposon insertion in the gumD gene of the HePS forming cluster of $K$. baliensis NBRC 16680 [20]. The gumD gene encodes the first step of HePS formation, whereas a loss of the functional gumD gene leads to a total disruption of the HePS production and secretion in K. baliensis NBRC 16680 . To clarify, if this mutation is a random event, or if it is a directed mutation possibly triggered by environmental factors, we performed an experimental series using different growth media. Different sugar combinations were tested (see 2.2) as well as stress inducing conditions like growth in ethanol (3\%) or in acetic acid $(0.6 \%)$ supplemented media. In addition, dilutions of the cryo-culture of $K$. baliensis NBRC 16680 were directly plated on $\mathrm{NaG}$ plates. A distinction was made between slimy glossy wild-type colonies (S) and rough dull mutant colonies $(\mathrm{R})$, which were transparent, held against the light. The NaG plates with the directly plated dilutions of the cryo-cultures from K. baliensis NBRC 16680 showed only wild-type colonies. At 0 h, i. e. after inoculation with the overnight culture, solely wild-type colonies could be identified in standard NaG-medium, with cell numbers of about $1 \times 10^{8} \mathrm{CFU} / \mathrm{mL}$ (Fig. 1a). On the contrary, after inoculation of $K$. baliensis NBRC 16680 in NaG medium supplemented with ethanol or acetic acid, rough colonies could be detected at time point 0 in one of the three biological replicates, respectively (Fig. $\left.1 b^{*} \mathrm{c}^{*}\right)$, which could have resulted from a too long contact to (and concomitant mutations in response to) acetic acid or ethanol. At $24 \mathrm{~h}$ the cell numbers of rough and wild-type strains were around $1,4 \times 10^{9} \mathrm{CFU} / \mathrm{mL}$ in the $\mathrm{NaG}$ medium and bacteria merged already into the starvation phase, with final cell counts of about $1 \times 10^{9} \mathrm{CFU} / \mathrm{mL}$ after $48 \mathrm{~h}$ (Fig. 1a). In 

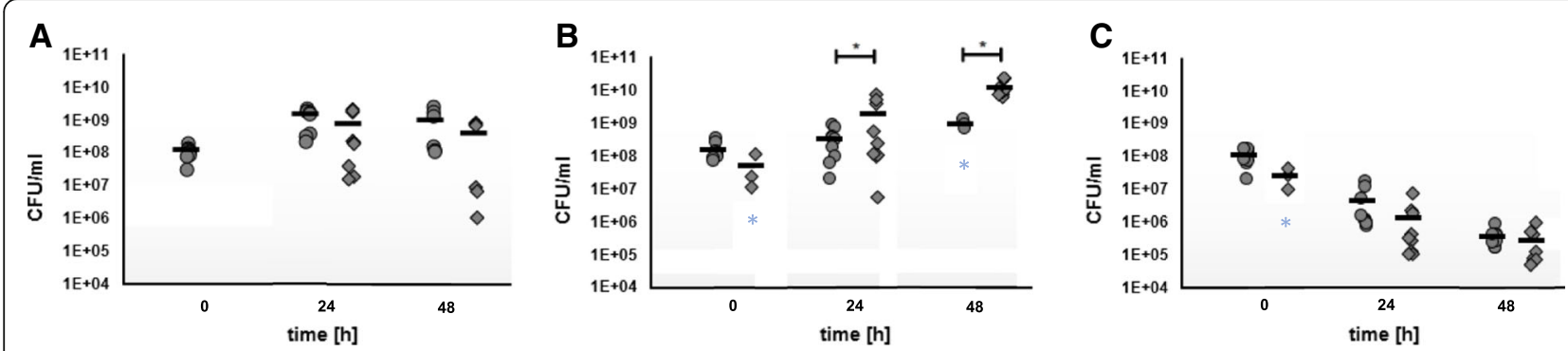

Fig. 1 Growth of K. baliensis NBRC 16680 in different media and influence of the provided carbon source on the morphology switch to a rough colony morphology ( $\Delta$ gumD). a Growth of K. baliensis NBRC 16680 in NaG medium, $n=9$ replica: wild-type $(\bullet), \Delta$ gumD ( $)$, mean value (一). b Growth of $K$. baliensis NBRC 16680 in NaG medium with ethanol (NaG-EtOH, 3\%), $n=9$ replica, * means that only $n=3$ replica were above the detection limit of $10^{4} \mathrm{CFU} / \mathrm{mL}$ : wild-type $(\bullet), \Delta g u m D(\bullet)$, mean value $(-)$.Asterisks centered over the error bars indicate the relative level of the p-value. In general, "** means $p<0.05$. (c) Growth of $K$. baliensis NBRC 16680 in NaG medium with acetic acid (NaG-AA, 0.4\%), $n=9$ replica, * means that only $n=3$ replica were above the detection limit of $10^{4} \mathrm{CFU} / \mathrm{mL}$ : wild-type $(\bullet), \Delta g u m D(\bullet), \operatorname{mean}$ value $(\boldsymbol{-})$

standard $\mathrm{NaG}$ medium the number of wild-type colonies exceled the number of mutant colonies or showed approximately equal numbers of wild-type and mutant colonies. During stress-inducing conditions (NaG-EtOH, NaG-AA), however, for $\mathrm{NaG}-\mathrm{EtOH}$ an inverted picture emerged. At both survey marks $(24 \mathrm{~h}, 48 \mathrm{~h}$ ) significantly more mutant (R) than wild-type colonies were detectable, with around ten-power difference (Fig. 1b). After $48 \mathrm{~h}$ only in three of nine cases, wild-type colonies with a detection limit above of $10^{4} \mathrm{CFU} / \mathrm{mL}$ could be detected (Fig. $1 \mathrm{~b}^{*}$ ). In the NaGAA medium, a continuous reduction of the cell numbers could be observed, in which the number of wild-type colonies always exceeded the number of mutated colonies (Fig. 1c).

In order to verify a possible integration of a mobile element in the gumD gene [20], or in front of the gumD gene, random colony $\mathrm{PCR}$ reactions were carried out, with a forward primer (G4F_Fw) targeting a location in front of the gumD gene (1.471.189-1.471.208 bp) and a reverse primer (TE-Rv) targeting the mobile element (Additional file 1) (Fig. 2b). Subsequently, the obtained PCR fragments were sequenced. For each mutated colony, a transposon insertion in the region of the gumD gene could be identified (Fig. 2c). These insertions, however, were not always located at the same site, but in a defined region of about $300 \mathrm{bp}$, around and in the gumD gene (Fig. 2c). Furthermore, it could be observed that in certain areas an integration of the mobile element occurred more often than in other areas, like up to nine times at $1471567 \mathrm{bp}$.

\section{Influence of the polE gene on HePS formation and composition of $K$. baliensis NBRC 16680}

In order to decode the role of the polE gene during pellicle formation of $K$. baliensis NBRC 16680 a polE deletion was carried out (see 2.3), with a markerless deletion system established by Kostner et al. [22, 24]. The pellicle forming ability of $K$. baliensis NBRC $16680 \mathrm{R} \Delta$ polE was further analyzed under static conditions in NaGmedium for 5 days. The growth behavior, as well as the HePS production, was compared with the wild-type and the rough mutant strain of $K$. baliensis NBRC 16680. All three $K$. baliensis strains showed pellicle formation after three days (Fig. 3a). For the wild-type strain of $K$. baliensis NBRC 16680 as well as for the rough mutant strain, a distinct pellicle formation at the edge of the test-tube was visible, which spreads over the entire boundary surface after three days. K. baliensis NBRC $16680 \mathrm{R} \Delta$ polE showed only a slight pellicle production (Fig. 3a). The physiology of the pellicle was different from the other two $K$. baliensis strains, instead of a surface spanning layer, only a loose conglomerate was present. The time for pellicle formation, also varied between the three strains. In comparison to the other $K$. baliensis strains, the pellicle of $K$. baliensis NBRC $16680 \mathrm{R} \Delta$ polE was only scarcely visible after three days of static incubation. During cultivation of the three $K$. baliensis strains (NBRC 16680, NBRC $16680 \mathrm{R}$ and RApolE) under shaking conditions, no significant aberration in the growth behavior could be observed (Fig. 3b). In case of the HePS formation in shaking cultures with NaG medium, after $48 \mathrm{~h}$ a slight HePS production of $K$. baliensis NBRC $16680 \mathrm{R}$ ApolE could be demonstrated, with HePS amounts of $180 \mathrm{mg} / \mathrm{L}$ (Fig. 3c). The rough mutant $K$. baliensis strain, which differs only in the presence of an intact polE gene from K. baliensis NBRC $16680 \mathrm{R} \Delta$ polE, showed no EPS production in shaking cultures (Fig. 3c). The wild-type strain of $K$. baliensis NBRC 16680 with an intact gum- and pol-cluster, showed the highest EPS production under shaking conditions, with 1,73 g/L EPS.

K. baliensis NBRC 16680 HePS was furthermore isolated from shaking cultures and the monomer compositions were determined. It was possible to obtain pellicle EPS from the rough mutant strain ( $K$. baliensis NBRC $16680 \mathrm{R})$, as well as EPS from shaking cultures from the K. baliensis NBRC 16680 wild-type strain and the polE 
A
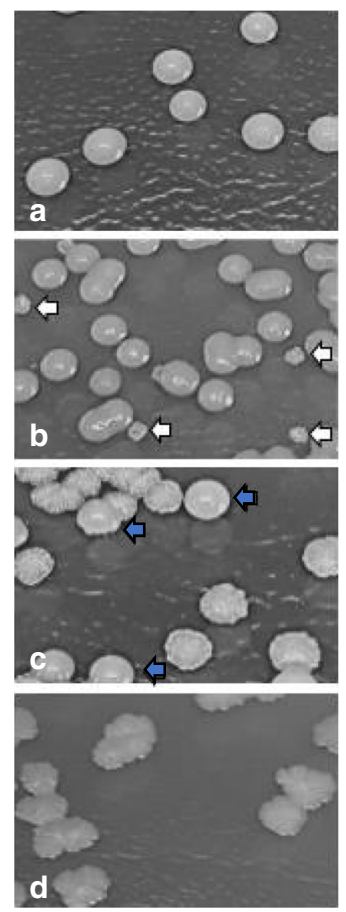

B
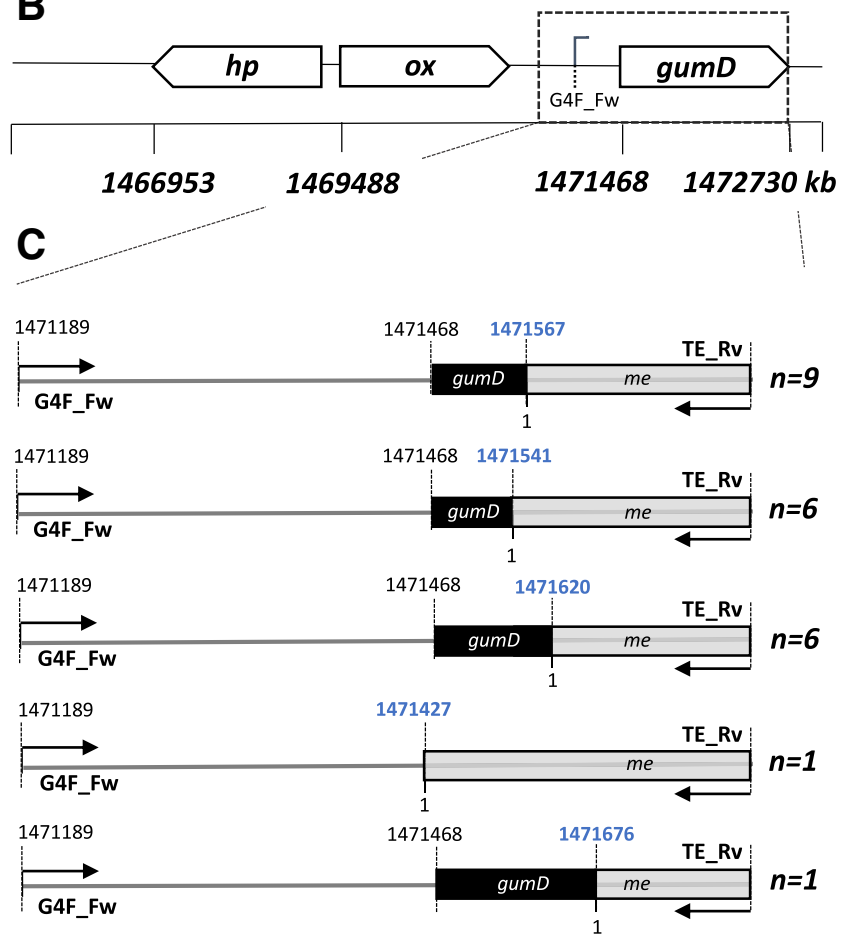

Fig. 2 Morphology and genetic switch of K. baliensis NBRC 16680 wild-type during cultivation in different media (a) In (a), growth of K. baliensis NBRC 16680 on NaG agar plates, plated at time point one after inoculation in NaG medium (0 h). Growth of K. baliensis NBRC 16680 on NaG agar plates, plated after $48 \mathrm{~h}$ of incubation in NaG medium (b), NaG-AA medium (c) and NaG-EtOH medium (d). Rough mutant colonies $(\Delta$ gumD) are indicated via a white arrow. Wild-type colonies are marked with a grey arrow. b) Shows a section of the gum-cluster of K. baliensis NBRC 16680 with the genomic location of the gumD gene (1471468-1,472,730 bp), oxidoreductase gene (ox, 1,469,488-1,470,627 bp) and a gene coding for a hypothetical protein ( $h p, 1,467,916-1,469,289$ bp), based on JU Brandt, Jakob, F., Behr, J., Geissler, A.J., Vogel, R.F. [20]. Random colony PCRs of the respective rough colonies were carried out, targeting the transposon insertion side, using a genomic primer (G4F_FW) and a primer, targeting the mobile element (TE_Rv). PCR products were subsequently sequenced. (c) Shows a schematic representation of the transposon insertion at the gumD locus in the rough colonys of $K$. baliensis NBRC 16680. The mobile element (me) is shown as grey bar with the corresponding insertion locus written in bold blue. The frequency of the found insertion site is marked on the left side, as $n=x$

deficient mutant, since for K. baliensis NBRC 16680 R, no EPS formation could be detected under shaking conditions. Because of the impaired pellicle formation of $K$. baliensis NBRC $16680 \mathrm{R}: \Delta$ polE (even during 14 days of cultivation in $30 \mathrm{~mL}$ cell culture flasks), no adequate amounts of EPS could be isolated for the monomer analysis. The monomer composition of wild-type $K$. baliensis NBRC 16680 HePS was composed of Dglucose, D-mannose and D-galactose (Fig. 3d). The statically cultivated rough mutant strain of $K$. baliensis, which is not able to produce HePS via the gum-cluster, showed a divergent monomer distribution, with generally higher amounts of D-mannose $(46,2 \pm 3,20 \%)$, and a consequently lower D-glucose $(33,9 \pm 5,03 \%)$ and Dgalactose $(19,9 \pm 1,83 \%)$ level (Fig. $3 \mathrm{~d}$ ). The HePS derived from shaking cultures of the polE deficient $K$. baliensis NBRC $16680 \mathrm{R}$ mutant showed a similar monomer distribution as the pellicle HePS of K. baliensis NBRC $16680 \mathrm{R}$, but with slightly variable percentages (Fig. 3d). Compared to K. baliensis NBRC 16680 R, a smaller proportion of D-glucose $(21,8 \pm 1,03 \%)$ was observable, while the proportion of D-mannose $(51,4 \pm 1,20 \%)$ was still higher.

\section{Physiological effects of $\triangle g u m D$ and $\triangle g u m D+\Delta p o l E$ mutations}

Since the insertion of a mobile element into the gumD gene of the gum-cluster of K. baliensis NBRC 16680 appears to be a mechanism affected by external factors, the question arises, whether this is a physiological adaptation of the bacterium to changes in its external environment. Therefore, the growth behavior of the different $K$. baliensis strains, under different cultivation conditions, was investigated. $K$. baliensis NBRC 16680 and DSM 14400, K. baliensis NBRC $16680 \mathrm{R}$ and the $\triangle$ polE mutant of the rough $K$. baliensis strain were plated on $\mathrm{NaG}$-medium plates, which were supplemented with different acetic acid $(0.1 \%, 0.2 \%, 0.3 \%, 0.4 \%$, $0.5 \%, 0.6 \%, 0.7 \%, 0.8 \%, 0.9 \%$ and $1 \%)$ and ethanol $(1 \%, 2 \%$, $3 \%, 4 \%, 5 \%, 6 \%, 7 \%, 8 \%, 9 \%$ and $10 \%)$ concentrations. Furthermore, the growth behavior of $K$. baliensis DSM 14400 


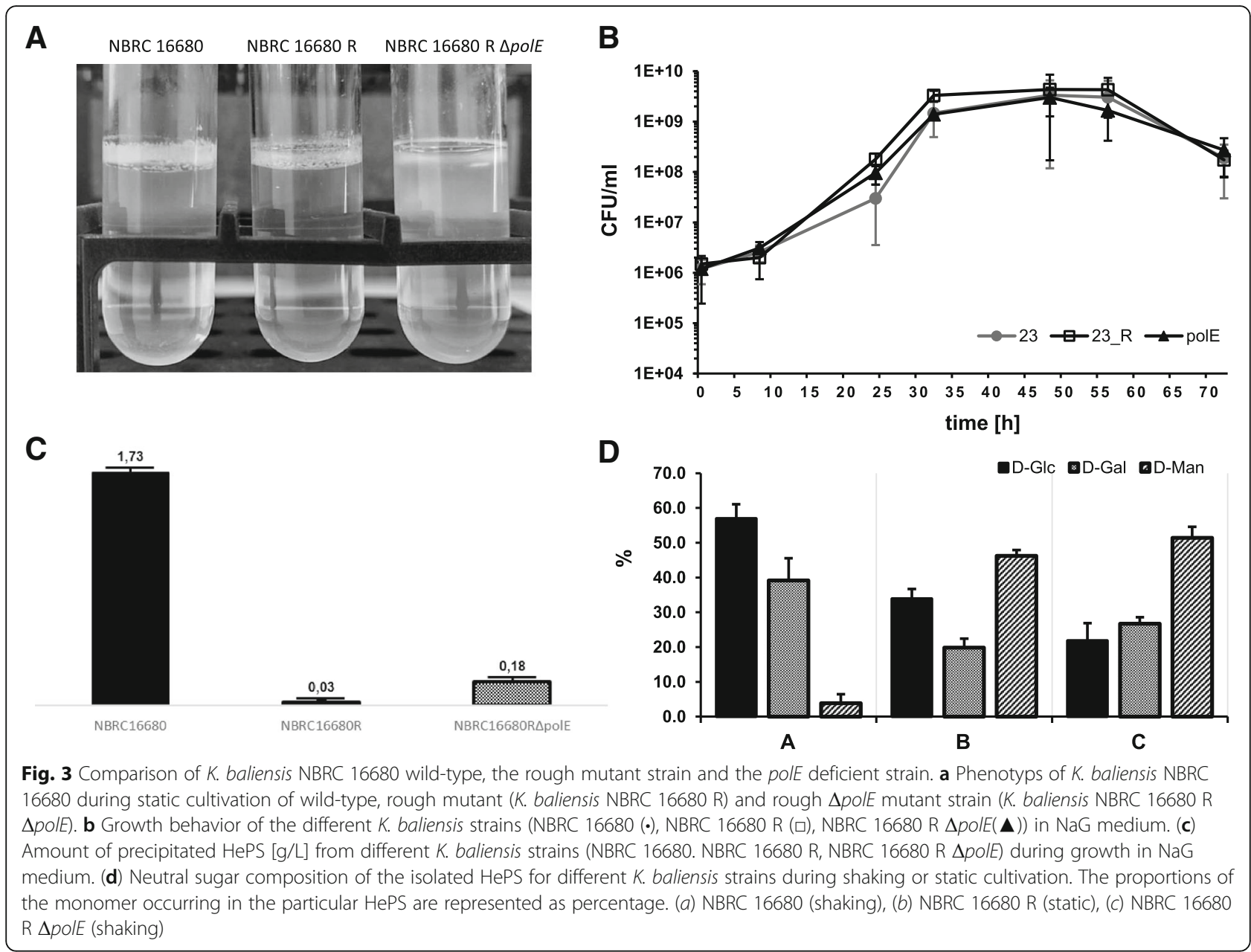

was additionally tested, to investigate the variability in the growth behavior between two different wild-type strains of K. baliensis. K. baliensis DSM 14400 forms a HePS which is also composed of D-glucose, D-galactose and D-mannose, but with a deviating ratio compared to NBRC 16680 [20]. After a cultivation period of three days, distinct differences in the growth behavior of the different strains could be observed. Acetic acid had a significant influence on the growth of the different $K$. baliensis NBRC 16680 strains, while $0.7 \%$ acetic acid was the highest concentration, at which colony formation on agar plates was still possible for Kozakia strains NBRC 16680 R and DSM 14400 (Fig. 4a). The K. baliensis NBRC 16680 wild-type and the $\triangle p o l E$ mutant of the rough $K$. baliensis NBRC 16680 strain were not able to form colonies above $0.6 \%$ of acetic acid. In case of growth on NaG-EtOH plates, K. baliensis NBRC $16680 \mathrm{R}$ and $K$. baliensis NBRC $16680 \Delta p o l E$, showed the highest EtOH tolerance, whereas $K$. baliensis NBRC 16680 R could even grow at $10 \% \mathrm{EtOH}$. Both wild-type strains of $K$. baliensis (NBRC 16680, DSM 14400) showed only poor growth behavior upon $7 \% \mathrm{EtOH}$ and no growth at all, above $8 \% \mathrm{EtOH}$ in the medium (Fig. 4b).
Furthermore, the effect of acetic acid and ethanol on the growth behavior of the different $K$. baliensis strains was monitored under static cultivation, by measuring the dry weight of the cells. It has to be noted, that the secreted, gum-cluster based HePS of the wildtype strain from $K$. baliensis NBRC 16680 was largely removed by centrifugation in advance. However, it can still slightly contribute to the dry weight as a small residue, which is still connected with the bacteria. In the $\mathrm{NaG}$ medium with $0.6 \%$ of acetic acid, the rough mutant strain displayed the fastest growth and reached the highest dry weight, after 7 days $(1,77 \pm 0.19 \mathrm{mg} / \mathrm{ml})$. The wild-type strain of $K$. baliensis NBRC16680 showed slightly reduced final dry weight $(1,64 \pm 0.04 \mathrm{mg} / \mathrm{ml})$, but an offset $\log$ phase resulting in a slower growth rate than the rough mutant strain (Fig. 5a). Similar results were obtained for the growth of the corresponding strains in $\mathrm{NaG}$ medium with 3\% ethanol. K. baliensis NBRC16680 $\mathrm{R}$ exhibited the fastest growth, with a final dry weight of $1,17 \pm 0.16 \mathrm{mg} / \mathrm{ml}$. For $K$. baliensis NBRC16680 and the $\triangle p o l E$ mutant strain, a markedly reduced growth could be demonstrated (Fig. 5b). 
A

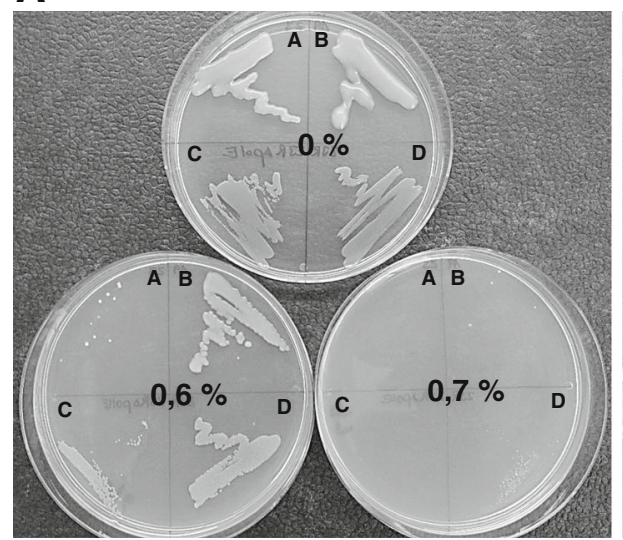

B

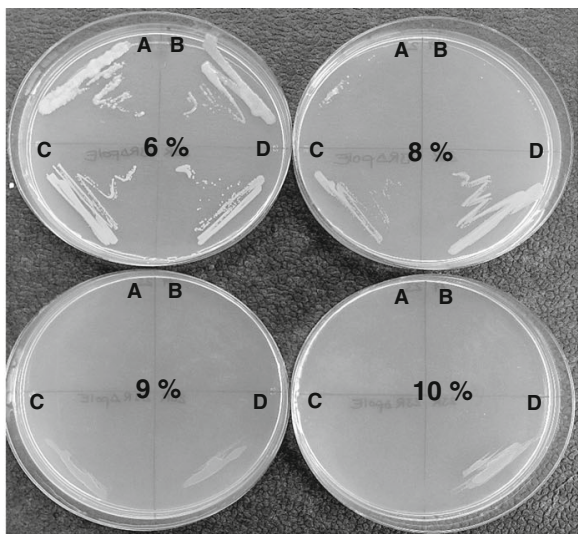

Fig. 4 Effect of acetic acid and ethanol on the growth behavior of different $K$. baliensis strains (a) Effect of acetic acid on growth of different $K$. baliensis strains (DSM 14400 (a), NBRC 16680 (b), NBRC 16680 R ApolE (c), NBRC 16680 R (d)) at different acetic acid concentrations (0\%, 0.6\%, 0.7\%). (b) Effect of ethanol on growth of different K. baliensis strains (DSM 14400 (a), NBRC 16680 (b), NBRC 16680 R $\Delta p o$ IE (c), NBRC 16680 R (d)) at different ethanol concentrations $(6 \%, 8 \%, 9 \%, 10 \%)$

\section{Discussion}

K. baliensis NBRC 16680 produces and secretes large amounts of HePS via a gum-cluster encoded HePS biosynthesis. By insertion of a mobile element into the gumD locus of $K$. baliensis NBRC 16680 a mutant strain of $K$. baliensis is formed ( $K$. baliensis NBRC $16680 \mathrm{R}$ ), which is unable to produce and secrete the gum-cluster derived HePS [20]. After cultivation of K. baliensis NBRC 16680 in standard or modified media (NaG, NaG-EtOH, NaG-AA), K. baliensis NBRC 16680 rough mutant strains were more frequently found in the presence of ethanol in the medium. For $\mathrm{AAB}$ an induced loss of various physiological properties has been observed, such as acetic acid resistance [30], ethanol oxidation, pellicle formation [31], and bacterial cellulose synthesis. The genetic mechanisms behind these instabilities is often unclear. Takemura et al. [32] reported that the loss of the ethanol oxidation ability in A. pasteurianus NC11380 occurs by an insertion of a mobile element into the alcohol dehydrogenase-cytochrome c gene, resulting in the loss of alcohol dehydrogenase activity. This has also been demonstrated for A. pasteurianus NCI 1452, where an insertion sequence element (IS) is associated with the inactivation of the alcohol dehydrogenase gene [33]. Gene inactivation provoked by transposable elements could also be demonstrated for EPS forming clusters of AAB, like the cellulose synthase operon. In A. xylinum ATCC 23769, an IS element caused insertions $0.5 \mathrm{~kb}$ upstream of the cellulose synthase gene, associated with spontaneous cellulose deficiency [34]. In both cases, it was not possible to sustain revertants of the cellulose synthesis and ethanol oxidation

\section{A}

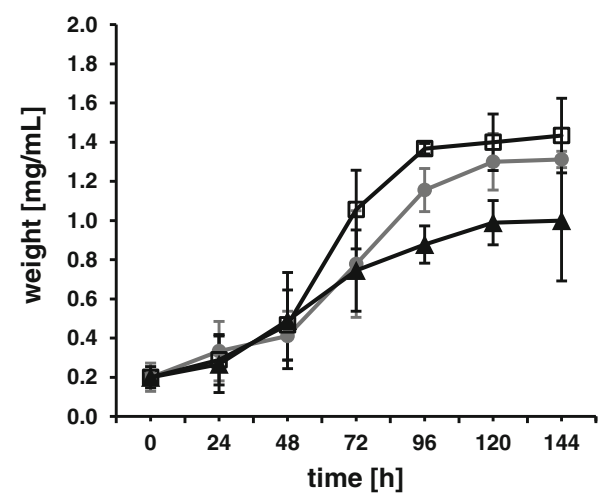

B

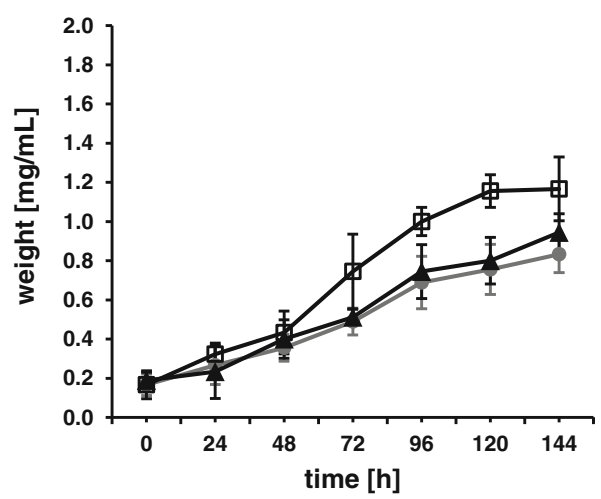

Fig. 5 Growth behavior of different $K$. baliensis strains during static cultivation in altered media (a) Growth behavior of the different $K$. baliensis

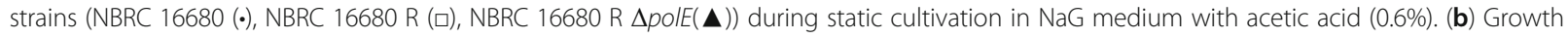
behavior of the different $K$. baliensis strains (NBRC $16680(\cdot)$, NBRC 16680 R (口), NBRC 16680 R $\Delta p o$ IE( $(\mathbf{\Delta})$ ) during static cultivation in NaG medium with ethanol (3\%) The growth was monitored by measuring the dry weight of cells 
insufficient mutant strains, possibly as a consequence of remaining directed repeats (DR) of the IS element after relocation. Also in case of one previously investigated $K$. baliensis NBRC $16680 \mathrm{R}$ mutant strain, the formation of directed repeats at the transposon insertion side could be observed [21]. Moreover, insertions of the mobile element in front of the gumD locus of the R strains as detected in the present study could result in a blocked transcription of gumD due to the presence of an energy-rich stem loop structure in the mobile element possibly causing rho-independent transcription termination [20]. It can actually not be ruled out that further mutations in the genome of $K$. baliensis NBRC 16680 simultaneously occurred. However, transposon insertion at the gumD locus of $K$. baliensis NBRC 16680 seems to be directly involved in R phenotype formation, since all of the 23 PCR checked R mutants exhibited the transposon insertion side at the gumD locus.

Morphotype variations, including the transition from a mucoid to a non-mucoid phenotype, are common events within the family of Acetobacteraceae, especially for Acetobacter species. This phenotypic change is often connected with the ability of the bacteria to form a pellicle on the medium surface $[10,11]$. The pellicle is an assemblage of cells that permits them to float on the medium surface during static cultivation and ensures a high state of aeration. It was also shown that pellicle production could be associated with a change from a smooth phenotype to the rough, pellicle-forming strain. This change is accompanied by a transformation from secreted EPS to CPS, which could serve as a better barrier against ethanol [18]. Also the rough mutant of $K$. baliensis NBRC 16680 is still able to form a pellicle under static cultivation [20], suggesting that a second cluster, instead of the gum-cluster, is responsible for pellicle construction. For different Acetobacter strains, it has been shown, that the so-called pol-cluster is responsible for pellicle formation [35]. The polABCDE cluster shows a high level of homology to the $r f b B A C D$ genes of Gramnegative bacteria, which are involved in dTDP-rhamnose synthesis [36]. The polE gene has already undergone several assignments, since it has a relatively low homology level to glycosyltransferases, in general. A disruption of the polE gene in A. tropicalis SKU1100. however, leads to a defect in pellicle formation, thereby giving it a central role, either as rhamnosyl-transferase [35], or as galactosyl-transferase [11], which connects the CPS to the cell surface. Moreover, the mutant $\mathrm{Pel}^{-}$cells secreted EPS into the culture medium. To investigate the relationship between pol-cluster and pellicle/CPS formation in K. baliensis NBRC 16680. polE knockouts were carried out in $K$. baliensis NBRC $16680 \mathrm{R}$, which does not form a gum-cluster dependent HePS [20]. Furthermore, we were interested to see, if a polE knockout has an effect on the ethanol tolerance of the respective $K$. baliensis strain. The $\triangle$ polE mutant of $K$. baliensis NBRC $16680 \mathrm{R}$ showed the same rough colony morphology as the rough strain ( $K$. baliensis NBRC 16680 $\mathrm{R})$. In contrast to $A$. tropicalis SKU1100. K. baliensis NBRC $16680 \mathrm{R} \Delta$ polE was still able to form a pellicle on the surface, which was, however, only a loose conglomerate of cells and required considerably more time for formation. Furthermore, the $\triangle p o l E$ mutant was able to secrete small amounts of EPS into the medium. The incoherent pellicle could therefore be formed by the secreted EPS, thus leading to the formation of a weak EPS/ cell-layer on the surface. The secreted EPS showed a similar composition as the $K$. baliensis NBRC $16680 \mathrm{R}$ capsular HePS. This supports the hypothesis of Ali et al. [11] that PolE is responsible for CPS formation, via addition of some residue(s) that connect the HePS with the cell surface, e.g. $\beta$-d-galactopyranosyl residues. A polE gene deletion or interruption results in a switch from a rough CPS producing, to an EPS producing phenotype, connected with growth behavior variations [35].

It was shown that a change from a smooth phenotype to the rough phenotype is associated with an increased tolerance against acetic acid [35]. By static cultivation and in combination with growth experiments on $\mathrm{NaG}$ plates with different ethanol and acetic acid concentrations of the different $K$. baliensis strains (NBRC 16680, NBRC 16680 R, NBRC $16680 \mathrm{R} \triangle$ polE), variations in the growth behaviors could be observed. Additionally to $K$. baliensis NBRC 16680 a second $K$. baliensis strain (DSM 14400) was tested, to investigate the variability in the growth behavior between two wild-type strains of $K$. baliensis. The rough mutant strain could form colonies on $\mathrm{NaG}$ plates under both ethanol and acetic acid stress in contrast to the wildtype NBRC 16680 even at high acetic acid (0.7\%) and ethanol (10\%) concentrations. During static growth of $K$. baliensis NBRC 16680 and the rough mutant, a similar pattern compared to the $\mathrm{NaG}$ plates appeared, with higher growth rates of $K$. baliensis NBRC $16680 \mathrm{R}$ in NaG medium with acetic acid and ethanol. The $\Delta p o l E$ strain, however, showed a diminished growth on acetic acid (up to $0.6 \%$ ) and ethanol (up to $9 \%$ ) agar plates, as well as during steady state growth. It is assumed, that the knockout of the polE gene results in a change from CPS to EPS, whereas CPS serves as a better barrier against acetic acid [37]. This indicates that the CPS of K. baliensis NBRC $16680 \mathrm{R}$ should be involved (inter alia) in the protection against acetic acid and ethanol. The direct relationship between pellicle formation and acetic acid resistance could be proven for $A$. pasteurianus (IFO3283, SKU1108, MSU10), where the rough strains had clearly higher acetic acid resistance abilities than the smooth phenotypes, respectively [19]. The pellicle functions in this case as a biofilm-like barrier and prevents the passive diffusion of acetic acid into the cells [38]. Furthermore, Perumpuli et al. [18] could show, that ethanol in the medium significantly induced pellicle formation. This is in agreement with our observations for $K$. baliensis NBRC 16680, which 
mutated more frequently in $\mathrm{NaG}$ medium with ethanol, suggesting a directed mutation, which could at least partially be triggered under acetic acid fermenting conditions by ethanol or its oxidized product acetic acid.

K. baliensis DSM 14400 showed, similar to K. baliensis NBRC 16680 R, a high resistance against acetic acid, but was derogated by ethanol concentrations up to $8 \%$. The high tolerance of $K$. baliensis DSM 14400 against acetic acid shows, that this strain has a different defense strategy in dealing with acetic acid, compared to K. baliensis NBRC 16680. Both strains were isolated from different environments (DSM 14400 isolated from palm brown sugar, NBRC 16680 isolated from ragi [39]). K. baliensis DSM 14400 might, therefore, have been commonly confronted with higher acetic acid concentrations, while they represent a new environmental factor for $K$. baliensis NBRC 16680. In the genome of $K$. baliensis DSM 14400. a cellulose synthase operon was identified on plasmid 3 (pKB14400_3) in contrast to $K$. baliensis NBRC 16680 including genes encoding the three cellulose synthase subunits A, B and C [20], suggesting that additionally formed cellulose could act as barrier against acetic acid. This is also the case for Komagataeibacter (Ko.) xylinus E25, isolated from vinegar, which generally deals with high acetic acid concentrations. Via comparison of diverse pol clusters from different acetic acid bacteria, a direct genetic connection between the pol- and gum-like clusters can be observed in Ko. xylinus (Fig. 6). Ko. xylinus E25 contains no polE gene in its genome, but is well known to produce a pellicle polysaccharide consisting of bacterial cellulose [13] and is also able to produce an extracellular HePS called acetan, composed of D-glucose, D-mannose, D-rhamnose, and D-glucuronic acid [6, 40]. In case of Ko. xylinus E25, the pol-cluster is flanking the acetan producing gum-like cluster, with the polAB gene upstream and the polCD gene downstream of the cluster (Fig. 6a). Acetan includes rhamnosyl residues, whose activated form is processed by polABCD [35], coding for the enzyme of the TDP-rhamnose synthesis, connecting the acetan synthesis with the enzymes of the pol-cluster. The polE gene is missing in the Ko. xylinus E25 genome (GCA_000550765.1), possibly resulting in no HePS mediated pellicle formation, while a tight cellulose pellicle is commonly formed on the surface of the medium [41], which again contributes to increased acetic acid resistance of the bacterium [42]. This shows that the gum-like HePS biosynthesis and the pol-cluster are possibly related with each other and are most likely regulated according to the environmental requirements of the respective bacterium. A lack of oxygen, or an increasing ethanol concentration, could be a signal, which leads to an up-regulation of the polE gene in $K$. baliensis NBRC 16680 . This can take place in association with an ethanol or acetic acid triggered stress response, probably resulting in an induced deactivation of the gum clusters, via a transposon insertion.

In the genome of Gluconacetobacter (Ga.) diazotrophicus PAl5, no polE gene is present as well (Fig. 6b). In contrast to Komagataeibacter xylinus, Ga. diazotrophicus is an obligate endophytic bacterium that lives symbiotically $\left(\mathrm{N}_{2}\right.$-fixing) in the intercellular space of roots, stem and leaves of sugarcane plants [30]. It produces a HePS composed of D-glucose, D-galactose and Dmannose, whose production is most likely attributable to its gum-like cluster similar to K. baliensis [31]. The produced HePS plays a key role during plant colonization, as shown for the molecular communication between the colonized plants and Ga. diazotrophicus [32]. The genetic switch of $K$. baliensis NBRC 16680 wild-type to its rough mutant could indicate an environmentally driven conversion/adaptation of a formerly more plant associated $\mathrm{AAB}$ (wild-type) to an increasingly acetic acid producing $\mathrm{AAB}$ (rough mutant). Furthermore, pol-cluster mediated capsular pellicle polysaccharide biosynthesis and concomitant inactivation of excess HePS production and secretion seems to increase the tolerance against

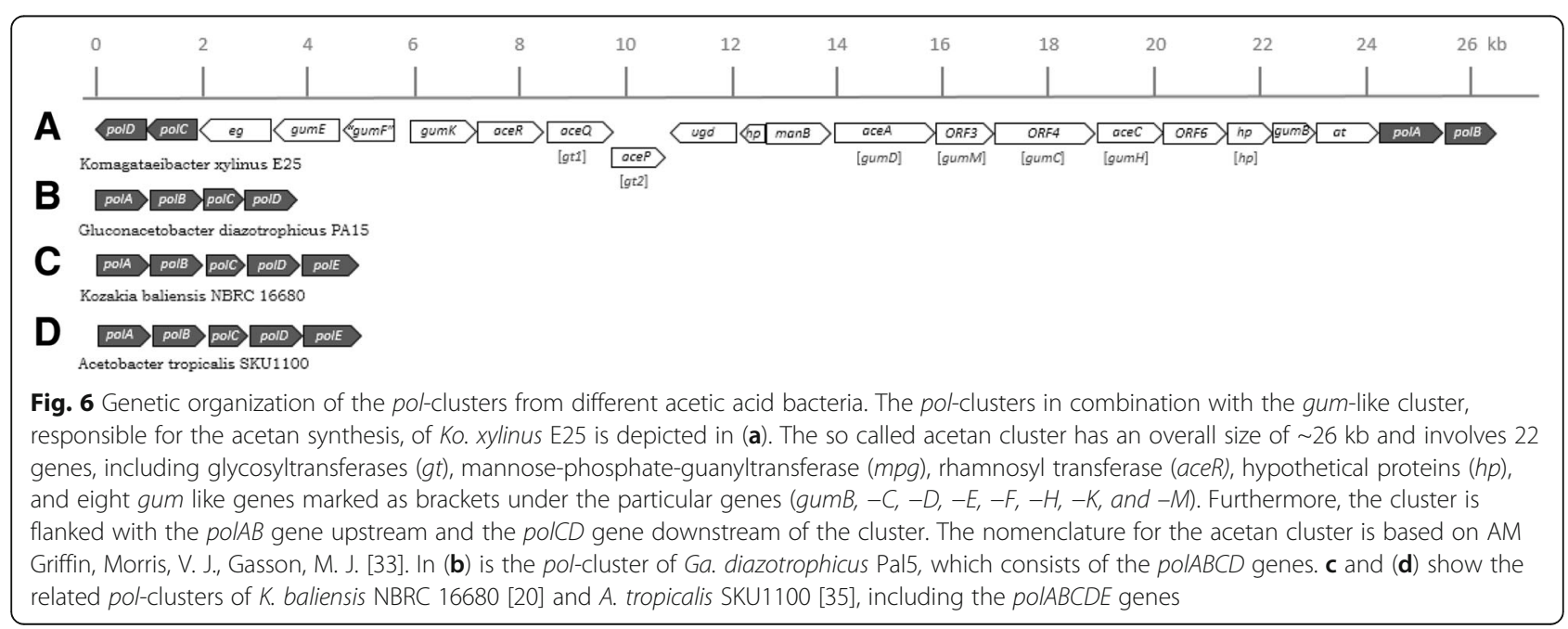


acetic acid in certain AAB such as $K$. baliensis NBRC 16680 , while specialized $A A B$ additionally produce tight cellulose pellicles, which are typical for extremely acetic acid tolerant starter cultures used in vinegar production such as Komagataeibacter xylinus.

\section{Conclusion}

In summary the results obtained in this study show, that a switch from the K. baliensis NBRC 16680 wildtype to a rough mutant strain leads to a significantly increased acetic acid and ethanol resistance. This increased tolerance is probably accompanied by a morphologic switch, from secreted HePS in the wild type to capsular HePS in the rough mutant strain (Fig. $3 \mathrm{~d})$. The polE gene turned out to be involved for the formation of the resulting CPS. Although the exact role of PolE is still unknown, the results presented here show that $K$. baliensis NBRC $16680 \mathrm{R} \Delta$ polE displays a reduced tolerance against acetic acid and ethanol, most likely caused by a lack of cell-bound CPS and thus of pellicle formation. Since the morphological change is not reversible, this can also be understood as an adaptive evolutionary step of $K$. baliensis NBRC 16680 resulting in a shift of its ecological niche more towards an acetic acid-rich milieu.

\section{Additional files}

Additional file 1: Primers used for polE gene deletion in $K$. baliensis NBRC16680 RTable of primers used fort the polE gene deletion in $K$. baliensis NBRC 16680 R. (PPTX 341 kb)

Additional file 2: Deletion of the polE gene (A0U90_11950).The deletion mechanism is depicted in (A) displayed with the particular basic vector pKos6b. The deletion of the polE gene (A0U90_11950) is shown in (B). In (C) Agarose gel of colony PCR verifying the deletion of the polE gene in the genome; lane 1 showing $K$. baliensis NBRC $16680 \mathrm{R}$ with the polE gene (3000 bp), lane 2 showing $K$. baliensis NBRC $16680 \mathrm{R}$ with a polE deletion $(\triangle p$ polE), with a PCR product of $1950 \mathrm{bp}$. (PPTX $418 \mathrm{~kb}$ )

\begin{abstract}
Abbreviations
AA: Acetic acid; AAB: Acetic acid bacteria; acs: Cellulose synthesizing operon; bcs: Cellulose synthesizing operon; CPS: Capsular polysaccharide; DSM: Deutsche Sammlung von Mikroorganismen; EPS: Exopolysaccharide; EtOH: Ethanol; G.: Gluconobacter; Ga:: Gluconacetobacter, Gal: Galactose; Glc: Glucose; gum: Protein involved in HePS biosynthesis (derived from X. campestris); HEPES: 2-(4-(2Hydroxyethyl)-1-piperazinyl)-ethansulfonsäure; HePS: Heteropolysaccharide; HoPS: Homopolysaccharide; HPLC: High-performance liquid chromatography; K: Kozakia; KM: Kanamycin; Ko: Komagataeibacter; Man: Mannose; MWCO: Molecular weight cut-off; NaG: Modified sodium-gluconate medium; NBRC: Biological Research Centre NITE, Japan; OD: Optical density; pol: Genes involved in pellicle formation; R: Rough strain; rfb: Genes involved in dTDPrhamnose synthesis; $X$ : Xanthomonas
\end{abstract}

\section{Acknowledgements}

We want to thank Prof. Dr. Wolfgang Liebl, Dr. Armin Ehrenreich and Dr. David Kostner (Department of Microbiology, Technical University of Munich) for giving us the opportunity to construct a $\Delta$ polE deletion mutant in $K$. baliensis NBRC $16680 \mathrm{R}$ with their developed gene deletion system.

\section{Funding}

This work was supported by the German Research Foundation (DFG) and the Technische Universität München within the funding program Open Access Publishing. Part of this work was funded by the German Federal Ministry for Economic Affairs and Energy via the German Federation of Industrial Research Associations (AiF) (FEl); project number AiF 18071 N. The funder had no role in the design, analysis, interpretation or writing of the manuscript.

Availability of data and materials

All data generated or analyzed during this study are included in this published article and its Additional files.

\section{Authors' contributions \\ $J U B, F J$ and RFV were involved in planning the experimental setup and writing the manuscript. JUB performed the main experimental work and FLB was involved in the implementation of the polE knockout system. JUB evaluated the data and wrote the main text of the manuscript. All authors read and approved the final manuscript.}

Ethics approval and consent to participate

Not applicable.

\section{Consent for publication}

Not applicable.

\section{Competing interests}

The authors declare that they have no competing interests.

\section{Publisher's Note}

Springer Nature remains neutral with regard to jurisdictional claims in published maps and institutional affiliations.

Received: 20 April 2017 Accepted: 10 July 2017

Published online: 10 August 2017

References

1. Roberts IS. The biochemistry and genetics of capsular polysaccharide production in bacteria. Annu Rev Microbiol. 1996;50:285-315.

2. Ferreira AS, Silva IN, Oliveira VH, Cunha R, Moreira LM. Insights into the role of extracellular polysaccharides in Burkholderia adaptation to different environments. Front Cell Infect Microbiol. 2011;16(1):1-9.

3. Jakob F. Novel fructans from acetic acid bacteria. Doctoral Dissertation, Freising, Germany: Technische Universität München; 2014.

4. Jakob F, Meißner D, Vogel RF. Comparison of novel GH 68 levansucrases of levan-overproducing Gluconobacter species. Acetic Acid Bacteria. 2012;1(1):2.

5. Jakob F, Pfaff A, Novoa-Carballal R, Rübsam H, Becker T, Vogel RF. Structural analysis of fructans produced by acetic acid bacteria reveals a relation to hydrocolloid function. Carbohydr Polym. 2013;92(2):1234-42.

6. Jansson P, Lindberg J, Wimalasiri KMS, Dankert MA. Structural studies of acetan, an exopolysaccharide elaborated by Acetobacter xylinum. Carbohydr Res. 1993;245:303-10.

7. Kornmann H, Duboc P, Marison I, Stockar U. Influence of nutritional factors on the nature, yield, and composition of exopolysaccharides produced by Gluconacetobacter xylinus 1-2281. Appl Environ Microbiol. 2003;69(10):6091-8.

8. Brown RM, Willison JH, Richardson CL. Cellulose biosynthesis in Acetobacter xylinum: visualization of the site of synthesis and direct measurement of the in vivo process. PNAS. 1976;73(12):4565-9.

9. Yamada $Y$, Pattaraporn $Y$, Vu L, Thi H, Yuki M, Duangjai O, Somboon T, Yasuyoshi N. Description of Komagataeibacter gen. nov., with proposals of new combinations (Acetobacteraceae). J Gen Appl Microbiol. 2012;58(5): 397-404.

10. Moonmangmee S, Kawabata K, Tanaka S, Toyama H, Adachi O, Matsushita K A novel polysaccharide involved in the pellicle formation of Acetobacter aceti. J Biosci Bioeng. 2002;93(2):192-200.

11. Ali IAl, Akakabe Y, Moonmangmee S, Deeraksa A, Matsutani M, Yakushi T, Yamada M, Matsushita K. Structural characterization of pellicle polysaccharides of Acetobacter tropicalis SKU1100 wild type and mutant strains. Carbohydr Polym. 2011;86(2):1000-6. 
12. Moonmangmee S, Toyama H, Adachi O, Teerakool G, Lotong N, Matsushita K. Purification and characterization of a novel polysaccharide involved in the pellicle produced by a thermotolerant Acetobacter strain. Biosci Biotechnol Biochem. 2001;66(4):777-83.

13. Saxena IM, Kudlicka K, Okuda K, Brown RM. Characterization of genes in the cellulose-synthesizing operon (acs operon) of Acetobacter xylinum: implications for cellulose crystallization. J Bacteriol. 1994;176(18):5735-52.

14. Wong HC, Fear AL, Calhoon RD, Eichinger GH, Mayer R, Amikam D, Benziman M, Gelfand DH, Meade JH. Emerick aW: genetic organization of the cellulose synthase operon in Acetobacter xylinum. Proc Natl Acad Sci U S A. 1990;87: 8130-4.

15. Azuma Y, Hosoyama A, Matsutani M, Furuya N, Horikawa H, Harada T, Hirakawa H, Kuhara S, Matsushita K, Fujita N, et al. Whole-genome analyses reveal genetic instability of Acetobacter pasteurianus. Nucleic Acids Res. 2009;37(17):5768-83.

16. Shimwell JLC, J. G. Mutant frequency in Acetobacter. Nature. 1964;201:1051-2.

17. Matsushita $\mathrm{K}$, Ebisuya $\mathrm{H}$, Ameyama M, Adachi $\mathrm{O}$. Change of the terminal oxidase from cytochrome a1 in shaking cultures to cytochrome o in static cultures of Acetobacter aceti. J Bacteriol. 1992;174(1):122-9.

18. Perumpuli PABN, Watanabe T, Toyama H. Pellicle of thermotolerant Acetobacter pasteurianus strains: characterization of the polysaccharides and of the induction patterns. J Biosci Bioeng. 2014;118(2):134-8.

19. Kanchanarach W, Theeragool G, Inoue T, Yakushi T, Adachi O, Matsushita K. Acetic acid fermentation of Acetobacter pasteurianus: relationship between acetic acid resistance and pellicle polysaccharide formation. Biosci Biotechnol Biochem. 2014;74(8):1591-7.

20. Brandt JU, Jakob F, Behr J, Geissler AJ, Vogel RF. Dissection of exopolysaccharide biosynthesis in Kozakia baliensis. Microb Cell Factories. 2016;15(1):170.

21. Wach A. PCR-synthesis of marker cassettes with long flanking homology regions for gene disruptions in S. cerevisiae. Yeast. 1996;12(3):259-65.

22. Peters B, Junker A, Brauer K, Mühlthaler B, Kostner D, Mientus M, Liebl W, Ehrenreich $A$. Deletion of pyruvate decarboxylase by a new method for efficient markerless gene deletions in Gluconobacter oxydans. Appl Microbiol Biotechnol. 2013;97(6):2521-30.

23. Tillett D, Neilan B. Enzyme-free cloning: a rapidmethod to clone PCR products independent of vector restriction enzyme sites. Oxford university press. 1999:27(19):e26.

24. Kostner D, Peters B, Mientus M, Liebl W, Ehrenreich A. Importance of codB for new codA-based markerless gene deletion in Gluconobacter strains. Appl Microbiol Biotechnol. 2013;97(18):8341-9.

25. Hall PE, Anderson M, Johnston DM, Cannons RE. Transformation of Acetobacter xylinus with plasmid DNA by electroporation. Plasmid. 1992;28(3):194-200.

26. Creaven M, Fitzgerald RJ, O'Gara F. Transformation of Gluconobacter oxydans subsp. suboxydans by electroporation. Can J Microbiol. 1994;40(6):491-4.

27. Krajewski V, Simić P, Mouncey NJ, Bringer S, Sahm H, Bott M. Metabolic engineering of Gluconobacter oxydans for improved growth rate and growth yield on glucose by elimination of gluconate formation. Appl Environ Microbiol. 2010;76(13):4369-76.

28. Mostafa HE, Heller KJ, Geis A. Cloning of Escherichia coli lacZ and lacY genes and their expression in Gluconobacter oxydans and Acetobacter liquefaciens. Appl Environ Microbiol. 2002;68(5):2619-23.

29. Kaditzky SV, Rudi F. Optimization of exopolysaccharide yields in sourdoughs fermented by lactobacilli. Eur Food Res Technol. 2008;228:291-9.

30. Cavalcante A. V., Dobereiner, J.: a new acid-tolerant nitrogen-fixing bacterium associated with sugarcane. Plant Soil. 1988;108(1):23-31.

31. Bertalan M, Albano R, de Padua V, Rouws L, Rojas C, Hemerly A, Teixeira K, Schwab S, Araujo J, Oliveira A, et al. Complete genome sequence of the sugarcane nitrogen-fixing endophyte Gluconacetobacter diazotrophicus Pal5. BMC Genomics. 2009;10:450.

32. Meneses CHSG. Rouws, L. F. M., Simões-araújo, J. L., Vidal, M. S., Baldani, J. I.: exopolysaccharide production is required for biofilm formation and plant colonization by the nitrogen-fixing endophyte Gluconacetobacter diazotrophicus. Mol Plant-Microbe Interact. 2011;24(12):1448-58.

33. Griffin AM. Morris, V. J., Gasson, M. J.: genetic analysis of the acetan biosynthetic pathway in Acetobacter xylinum. Int J Biol Macromol. 1994;16(6):287-9.

34. Coucheron $\mathrm{DH}$. An Acetobacter xylinum insertion sequence element associated with inactivation of cellulose production. J Bacteriol. 1991; 173(18):5723-31.

35. Deeraksa A, Moonmangmee S, Toyama H, Yamada M, Adachi O, Matsushita K. Characterization and spontaneous mutation of a novel gene, polE, involved in pellicle formation in Acetobacter tropicalis SKU1100. Microbiology. 2005;151(Pt 12):4111-20.

36. Marolda CLVM. Genetic analysis of the dTDP-rhamnose biosynthesis region of the Escherichia coli WW187 (O7:K1) rfb gene cluster: identification of functional homologs of $\mathrm{rfbB}$ and $\mathrm{rfbA}$ in the $\mathrm{rff}$ cluster and correct location of the rffE gene. J Bacteriol. 1995;177(19):5539-46.

37. Deeraksa A, Moonmangmee S, Toyama H, Adachi O, Matsushita K. Conversion of capsular polysaccharide, involved in pellicle formation, to extracellular polysaccharide by galE deletion in Acetobacter tropicalis. Biosci Biotechnol Biochem. 2006;70(10):2536-9.

38. Kanchanarach $W$, Theeragool G, Inoue T, Yakushi T, Adachi O, Matsushita K. Acetic acid fermentation of Acetobacter pasteurianus : relationship between acetic acid resistance and pellicle polysaccharide formation. Biosci Biotechnol Biochem. 2010;74(8):1591-7.

39. Lisdiyanti $P$, Kawasaki H, Widyastuti $Y$, Saono S, Seki T, Yamada Y, Uchimura T Kozakia baliensis gen. Nov., sp. nov., a novel acetic acid bacterium in the a-Proteobacteria. Int J Syst Evol Microbiol. 2002;52:813-8.

40. Ishida T, Sugano Y, Shoda M. Effects of acetan on production of bacterial cellulose by Acetobacter xylinum. Biosci Biotechnol Biochem. 2002;66(8):1677-81.

41. Brown AJ. On an acetic ferment which forms cellulose. J Chem Soc. 1886; 49:432-9.

42. Toda K, Asakura T, Fukaya M, Entani E, Kawamura Y. Cellulose production by acetic acid-resistant Acetobacter xylinum. J Ferment Bioeng. 1997;84(3):228-31.

\section{Submit your next manuscript to BioMed Central and we will help you at every step:}

- We accept pre-submission inquiries

- Our selector tool helps you to find the most relevant journal

- We provide round the clock customer support

- Convenient online submission

- Thorough peer review

- Inclusion in PubMed and all major indexing services

- Maximum visibility for your research

Submit your manuscript at www.biomedcentral.com/submit
) Biomed Central 